\title{
Declining of Tuloni Biya: a Case Study
}

\author{
Sangeeta Das \\ Centre for the Study of Social Systems, School of Social Sciences,Jawaharlal Nehru \\ University. ORCID ID: ooo1-7858-o612. Email: sangeetadas.das762@gmail.com
}

Received February 15, 2017; Revised April 10, 2017; Accepted April 16, 2017; Published May 7, 2017.

\begin{abstract}
Assam had a tradition of public celebration of puberty, known as tuloni biya. Tuloni biya is ceremonially symbolic to wedding which is celebrated seven days after a girl attains her puberty. In present times, however, one can hardly see any public celebration of puberty. This practice of celebration of tuloni biya has undergone significant changes. Celebration of puberty is becoming a close family affair from a public one.This paper, therefore, attempts to look at the continuities and change in the practice of celebrating tuloni biya among Assamese society. The findings reveal that rituals and restrictions associated with puberty is still in place. It is only the celebration that is dying away. It may, therefore, be argued that puberty and menstruation is now beginning to be seen as a taboo subject in Assamese society, and thereby is kept confidential.
\end{abstract}

Keywords: puberty, tuloni biya, Assamese society

\section{Introduction}

Noted ethnographer and folklorist Arnold Van Gennep in his book "The Rites of Passage" (196o) argues that 'life of every individual is marked by a series of transition from one social status to another and every culture prescribes some rites (rituals) to depict and accompany that individual in transition' (Gennep, 1960:2). There are rites to mark the birth, death, puberty, marriage, etc. He further says that in every culture although the function to celebrate these events is different but the underlying objective is the same. Rituals are unique to every society and culture. These rituals are symbolic and meaningful and perform some specific function.

In this context, reference may be made to a rite called Shanti Biya or more popularly, tuloni Biya celebrated among the Hindus in Assam. Tuloni Biya is a ritual performed when a girl attains her puberty. It is a rite of passage which marks the phase of transition from being a girl into womanhood. This Hindu Assamese tradition of holding an occasion for girls who got her first period is an ancient tradition. However, one can see either a gradual decline in this practice or change in its nature from a public affair to a close family affair.

The gradual decline of tuloni biya, particularly in Urban areas, have a societal implication in addition to effecting traditional cultural practices. Menstruation is the visible symbol of pollution in Indian society. It is considered a tabooed topic and therefore, is prohibited to be discussed in public. But in Assam, a girl's first menstruation is celebrated publicly, which might be seen as an open-minded facet of Assamese society as compared to many other societies in India. The gradual decline of tuloni biya, thus, could be argued as a backward march of the Assamese society with respect to issues relating to women and menstruation.

(c) AesthetixMS 2016. This Open Access article is published under a Creative Commons Attribution Non-Commercial 4.0 International License (http://creativecommons.org/licenses/by-nc/4.o/), which permits non-commercial re-use, distribution, and reproduction in any medium, provided the original work is properly cited. For citation use the DOI. For commercial re-use, please contact editor@rupkatha.com. 
This paper, therefore, attempts to look at the continuities and change in the practice of celebrating tuloni biya among Assamese society. In doing so, the paper describes the traditional rituals associated with tuloni biya. Attempt will also be made to highlight those aspects of the rituals which are retained as well as those which have withered away. Finally, the paper will attempt a discussion, thereby producing conclusion.

\section{Method and Sample Size}

The study was conducted in Beltola, situated in the city of Guwahati, Assam during June 2016. Beltola, being a home locality, was a familiar field and thereby helped in identifying the respondents. Observation and Semi-structured interviews were used as tools for data collection. Not all questions were designed beforehand. In fact, a number of questions were prepared during the course of the study. Doing so was necessary in order to probe further or discuss specific issues in detail. For the purpose of this study, fifteen in- depth interviews were conducted over a period of fifteen days. The sample size consisted of fifteen women, four of which are home-makers, three government servants, one school teacher, two enterprenuer (one runs a beauty parlour and the other owns a photocopy shop) and one college student.

\section{Rituals of Tuloni Biya as Observed in the Past}

Various rituals and ceremonies marking the onset of first occurrence of menstruation is practiced in various states in India. In Maharastra and Orissa, the onset of first menstruation is celebrated as a changed in status. At her first menarche, a girl in Karnataka, is fed with dry coconut, milk, ghee, certain fruits and a mixture of jaggery and sesame seeds. Reference may be made to Leela Dube's article "On the Construction of Gender: Hindu Girls in Patrilineal India" which provides a detailed account of various menstruation rituals performed in India (Dube, 1988).

In many Indian cultures, puberty is linked to the process of flowering or blossoming, which is a necessary stage before fruits can appear (Dube, 1998: 13). Similarly in Assam, ceremony regarding puberty is also refer to as pusputsav and the the term puspitã means attaining puberty. Both the words has their roots in the Sanskrit word puspa which means flower. Thus, the pubertal stage is compared with flowering as it makes the girl capable to reproduce.

In so far as tuloni biya is concerned, until recently it was a ceremonially symbolic to wedding being celebrated seven days after a girl attains her puberty. Biya in assamese language means marriage and the word Shanti denotes the relief of parents when their daughter menstruates, which implies her capability of getting married and producing children (Das, 2014: 49). And the other term Tuloni or Tula/Tuliluwa means to be lifted. It connotes an elevation of a girl from childhood to adulthood (Gogoi, 1964: 32).

When a girl attained puberty she would go through a period of isolation. She used to be confined in a room, where a special bed spread with hay was laid for her. She would not be allowed to touch anything nor touched by anyone for seven days. This was because the girl would be considered chua, meaning impure (Gogoi, 1964: 33). For the first three days, she would be debarred from eating any solid cooked food. In these days, fruits and uncooked grams and pulses, milk and milk products were offered to her. The girl would also be made to follow some restrictions like not combing hair, not cutting nails, and would also not be allowed to see men nor men were allowed to see or touch her. A girl of her age would be made to accompany her from 
the first day onwards, which was known as suwali-parala-diya, meaning to guard the girl who had attained puberty (Gogoi 1964: 33).

On the fourth day, she would be bathed with maah-holodi, i.e., gram and turmeric with proper wedding rituals. A banana tree symbolising the girl's mock husband would be fixed at the spot where the girl would be bathed. Women of all ages would partake in this ritual and shower their blessings on the menstruating girl. After the bath, she would be made to wear the traditional assamese dress called mekhela -chador. From the fourth day till the seventh day, the girl woul be permitted to eat boil food once in a day in the evening after the sunset. This boil food was known as hobbis. Boil food generally comprise of boil rice and lentils and it had to be cooked in a clay pot by the girl herself.

The days of seclusion would come to an end with the coming of the seventh day. On this particular day, the girl would again be given a ritualistic bath in front of a banana tree and other women of the family and neighbourhood. After the ritualistic bath, the girl would be dressed like a bride and a big feast would be arranged for the friends, family and neighbours. The feast was seen as a magolik anusthan, i.e., an auspicious ceremony. As a tradition people often brought gifts for the bride. All this would be done to announce the girls newly acquired identity and the family's happiness (Das, 2014: 51).

Additionally, on the first day itself, a member of the family, especially, the mother would consult a priest and provide him with the date and time when the girl attained puberty. The priest would then make some astronomical calculation of the date and time to figure out hidndrances, if any, in the girl's future conjugal life. The morning hours were seen to be serene, therefore if a girl attained puberty in early morning, she was believed to be having a peaceful marital life and would be designated as padmini kanya. The first half of the day, before noon was considered a period of hustle and bustle and for a girl who attained puberty at this hour would be designated as siprani kanya, which means chanchal. Further, as the heat of the sun would reach its peak in the afternoon, one who attained puberty in the afternoon would be an ugro kanya, which signifies rage. And a girl who attained puberty in the evening, was referred to as a hostini kanya. Such woman were believed to become frustrated by evening as the tensions of the day accumulated in the mind and body by the evening (Das, 2014: 51).

For all kinds of kanyas, atonement would be prescribed by the priest for the betterment of the girl's marital life. If the astronomical calculation of the date and time of menarche indicate hindrances for a peaceful conjugal life, the priest would prescribe fasting, which may be from one week to one month and sometimes even a year (Das, 2014: 51). Other penances like wearing clothes of a certain colour on the seventh day, donating clothes and/or eatables, making a particular animal eat on a particular day and so on would be chalked out by the priest.

The above mentioned is the detailed account of the whole process of tuloni biya as oserved until ten years ago or so. I myself have gone through these rituals when I first attained my puberty. I happened to attain puberty in the evening and as a consequence was described a hostini kanya. As a penance, I was prescribes fasting for a period of one month. My own experience is a testament to the above mentioned rituals relating to puberty. Unlike in North India where menstruation has lawys been kept secret and dealt only by the female members of the society, in Assam, it used to be announced and celebrated. It may, therefore, be argued that there is seemingly contradictory attitude towards menstruation or puberty among the people of Assam. On the one hand, menstruation is seen to be something impure and therefore taboos are associated with it. On the other hand, however, it is seen as something auspicious and therefore celebrated, 
It is pertinent to mention here that in Assam not only menstruation of common girl is celebrated but menstruation of Goddess is also celebrated. Refernce may be made to the festival called Ambuvachi Mela. It is a celebration of Goddess Kamakhya's annual menstruation. Ambuvachi Mela takes place in the month of June every year. It is believed that during this period Goddess Kamakhya menstruates in order to prepare herself for her fertilizing work and so her temple remains close for three days for devotees. There is also an entire cessation from all ploughing, sowing and other farm work during this time (Crooke, 1919: 287). Thus, it can be argued that there is a deep relation between menstruation and the concept of purity and profanity. It is believed to be profane and hence there are taboos associated with menstruation, which is common for both woman and divine.

It is apposite to question at this point as to what is the source or rather origin of the taboos associated with menstruation? A number of anthropologists have attempted to explore the etiology of the taboos associated with menstruation since the prehistoric time. For instance, Bruno Bettelheim is of the view that menstruation and the related capacity of child bearing were once a source of jealousy to men. Therefore, in an attempt to make the two sexes equal, taboos were imposed on menstruating women (Bettelheim, 1962: 137). In a similar vien, Elizabeth Gould Davis sees the menstrual taboo as a vestige of the primitive matriarchal societies when the women in power used the taboo to make men respect and fear them. She goes on to mention that tales of danger to men from menstrual blood were narrated to little boys to make them obedient and respectful of women (Davis, 1972: 92).

The anthropological literature fails to provide any direct evidence linking the origin of menstrual taboos with one or the other sex. Yet, Janice Delaney and others, argued that the taboos were ostensibly enforced by men, who connected the women's menstrual cycle with the cycles of moon, the seasons, the flow of the tides, the darkness of the night covering the light of the sun and who feared such cosmic power in the apparent control of a member of their own species (Delaney, et al, 1988: 8).

Talking particularly about Indian culture, the Dharmashastras contain a number of restrictions for a menstruating women. It deals at some length with what a menstruating women should and should not do. Menstrual taboos are related to the myth of Indra assassinating Vritra. "In the Rig Veda, Vritra is depicted as the withholder of the waters, the demon of droughts, a snake or dragonlike figure who dwells in the rivers or celestial waters, or in a cavern in the earth. He lives in the caves with the cows. Indra kills Vritra with his thunderbolt, thus releasing the waters, the cows, and wealth, prosperity, and progeny" (Chawla, 1994: 2818). Of the many proscriptions in the Dharmashastras, a particular proscription provides that during her period, a woman shall not apply collyrium to her eyes, nor anoint her body, nor bathe in water; she shall sleep on the ground; she shall not sleep in the day-time, nor touch the fire, nor make a rope, nor clean her teeth, nor eat meat, nor look at the planets, nor drink out of a large vessel, or out of joined hands, or out of a copper vessel (Chawla, 1994: 2819). Thus, this proscription seems to be providing sanction to the rituals associated with tuloni biya in Assam.

\section{Tuloni Biya in Present times}

At a time when menstruation was widely considered a taboo topic and hardly any discussion on the topic was made possible, Assam was in a unique position of celebrating tuloni biya. However, this practice of celebrating menarche is fast declining in Assam. It may be noted here that similar 
rituals were performed in ancient Greece and Rome when boys and girls attained puberty or adulthood, which is neither discussed nor mentioned in present times.

People in Assam no longer celebrate tuloni biya like they used to ten years before. Although it has not completely vanished, its form has changed to a great extent. Many modifications have been done according to one's convenience and choice. The event of the celebration of first menstruation is being turned into a family affair without any big celebration, though the basic ritual may be still practiced as a mark of respect to cultural heritage. Infact, tuloni biya is almost in the phase of withering away from the assamese society.

The scene has changed a lot in the contemporary times among the educated people in town and cities. The reason for this is manifold. First and most important reason for its withering is that teen girls find it embarrassing to celebrate it with publicity. They would more prefer to keep it a private affair. Secondly, people in the present times do not have enough time to perform seven days of ritual. So they prefer to keep it short.

Reference may be made to Mitoo Das's ethnographic work (Das, 2008), where she argues that the restrictions and rituals regarding menstraution has become more liberal with the changing scenario. She rightly attributes this modification to the change in the family structure, that is, the from joint family to nuclear ones. As families are getting smaller with lesser number of women to control the domestic scene, the work pressure has increased which required women to work even during her menses (Das, 2008: 40). She further asserts that restrictions relating to menstruation are now followed or not followed as a matter of convenience.

An attempt in this section has been made to investigate the continuity and change in the practice of celebrating tuloni biya. Without substantial literature to draw upon, the account on this section is based on observation and interview reponse. The idea is to give a picture of tuloni biya as is observed in present times and people's perception towards it.

\section{Continuity and Change: Empirical Evidence}

In the present times, people hardly celebrate tuloni biya. Not celebrating tuloni biya does not, however, mean that the rituals are no longer observed. Rituals are very much in place and are observed as was always. Sandhya Das, a mother of a 15 year old, said, "We did not celebrate our daughter's menarche. However, I did make sure that she observes all the rituals. She was kept in seclusion for seven days. We did not let her go to school. All the rituals that my mother made me follow. I made my daughter follow them too. It is only that we did not announce her newly acquired sexual identity publicly by inviting people for the seventh day feast." On being asked as why they chose to observe the rituals and escape just the feast part? She replied, "The time is not the same as was ours. My sister who stays in delhi also did not celebrate her daughter's menarche, which was a year before our daughter attained puberty. In so far as rituals are concerned, they are for the good of our daughter."

In a similar line, Pratima Laskar, who owns a photocopy shop, also stressed that "Rituals related to a menarche is important for a girl's conjugal life. I believe that just as for a son, observing the restrictions and rituals associated with their parents' shradhya (funeral) ceremony is important. Similarly, the rituals and restrictions that a girl will follow on the first attainment of her puberty, will only repay in the form of a peaceful reproductive and conjugal life later. So, following the rituals are important. But inviting people and treating them require a huge amount 
of time and money, which could be avoided. Moreover, people now a days do not talk about issues related to menstruation."

On being asked if the rituals have also undergone changes Jamini Hazarika, who works at a government office, indicated towards a change in the ritual aspect as well. She maintained, "In present times, rituals have also been made flexible. For instance, girls' now are not made to sleep on hay spread bed but on a usual bed. The point is only to keep her separate and make sure she does not touch anything." She, further added, "In present times people themselves are not aware of all the rituals. They remember some and have forgotten some. They just make sure that the ritualistic bath on the fourth and seventh day is followed well."

In attempting to understand if menstruation is no longer seen as impure, respondents were asked about their opinion. To this Runu Das mentioned "Menstruation is still impure. It is the impure blood that comes out during menstruation. Not celebrating tuloni biya does not mean we no longer consider it impure. It is impure and therefore the girl is still kept in seclusion." She further added, "The social atmosphere has changed now. We no longer feel it's safe to disclose our daughter's newly acquired sexual identity. Therefore, we avoid letting a large number of people know it. However, observing the rituals is for the betterment of the girl. We still perform those rituals."

From the above account, it may be deduced that the rituals and restrictions associated with menarche are in tact and are observed even today. The celebration, however, has turned into a closed family affair from a hitherto community affair. The reasons for this change has been cited as lack of time and money, feeling of insecurity in disclosing the girl's sexual status, transformation of family structure from joint to nuclear one, and also fading away of the memories of the rituals in entirety.

\section{Discussion and Conclusion}

It is important to note that rituals and restrictions are two different concepts. A ritual is a religious or solemn ceremony consisting of a series of actions performed according to a prescribed order, while restriction indicates a state of being restricted. It is well established now that women have historically been restricted or rather discriminated on the pretext of one ritual or another. The rituals around menstruation also intend to restrict women. There is no denying of this fact. However, concern in this paper is with regard to decline in the practice of solemnizing tuloni biya. Declining of tuloni biya or similar rituals elsewhere in India is seen to be a positive change and mark of progressiveness for a society. However, the paper attempts to argue otherwise.

It may be argued that the gradual decline in the practice of celebrating tuloni biya in Assam does not indicate the withering of the idea of taboo associated with menstruation. Rather, it may be argued that the people of Assam have gradually started to see menstruation, as a taboo subject and therefore attempting to keep it secret.

The case in point can be verified by the fact that women till date are not allowed to enter the temple or offer prayers in their menstruating state. The restrictions prescribed for a menstruating women are very much in place, even in the present times. It is only the celebration of menarche that is gradually declining.

Based on the responses of the respondants, it becomes aptly clear that rituals associated with puberty are observed in the present times as well. The idea of impurity associated with 
puberty is also intact. However, what has changed is one's perception about the concept of puberty or menstruation. People in Assam now prefer to keep it undisclosed. As has been mentioned earlier, the feast and the celebration associated with tuloni biya was considered mangalik anusthan, meaning, auspicious ceremony. Therefore, the gradual decline of the ceremony indicates that the auspiciousness associated with puberty is dying out. In present times, puberty is just about impurity and hence, kept confidential. It can, therefore, be argued that puberty and menstruation in Assamese society is more of a taboo subject now than ever before. It, thereby, indicates a backward march for the Assamese society from openness to reticence with respect to issues relating to menstruation.

The idea should be to erode those practices that warrants restriction or oppression for women. But, it has been observed that the practices associated with menarche or menstruation are in place, with the exception of minor positive changes in the urban areas. The most problematic aspect of menstruation is the restriction to enter the temple. This restriction is continuing in Assamese society unchallenged. Continuation of the restrictions to enter a temple indicates that menstruation till date is seen as something polluted. Therefore, it will be utterly wrong to say that taboos associated with menstruation are gradually dying away and thereby celebration of tuloni biya also is declining. On the contrary, celebration of tuloni biya is gradually declining because auspiciousness associated with it is dying away.

\section{References}

Bettelheim, B. (1962), Symbolic Wounds: Puberty Rites and the Envious Male, New York: Collier.

Chawla, J. (1994), "Mythic Origins of Menstrual Taboo in Rig Veda", Economic and Political Weekly, Vol. 29, No. 43, pp. $2817-2827$.

Crooke, W. (1919), "The Cults of the Mother Goddesses in India", Folklore, Vol. 30, No. 4, pp. 282-308.

Das, M. (2008), "Menstraution as Pollution: Taboos in Simlitola, Assam", Indian Anthropologist, Vol. 38, No. 2, pp. 29-42.

Das, M. (2014), "Performing the 'other' in the self: reading Gender and Menstruation through Autoethnography”, Indian Anthropologist, Vol. 44, No.2, pp. 47-63.

Davis, E. G. (1972), The First Sex, Baltimore: Penguin Books.

Delaney, J. et al, (1988), The Curse: A Cultural History of Menstruation, Urbana and Chicago: University of Illinois Press.

Dube, L. (1988), "On the Construction of Gender: Hindu Girls in Patrilineal India”, Economic and Political Weekly, pp. WS 11- WSig.

Gennep, A. V. (1960), The Rites of Passage, Translated by Monika B. Vizedom and Gabrielle L.Caffee, London and Henley: Routledge and Kegan Paul.

Gogoi, N. K. (1964), Continuity and Change Among the Ahom, New Delhi: Concept Publishing Company.

Sangeeta Das is a doctoral student at the Centre for the Study of Social Systems, Jawaharlal Nehru University, New Delhi. She has been working in the area of Sociology of Religion. Her M. Phil Dissertation, title Ambubachi Mela in Kamakhya Temple in Assam: A Sociological Analysis was submitted in July 2013. Presently she is working on her PhD Thesis, title Gender and Caste in Contemporary Tantric Practices in Assam, which is due to be submitted in July 2018. Email: sangeetadas.das762@gmail.com. 